University of Nebraska - Lincoln

DigitalCommons@University of Nebraska - Lincoln

Faculty Publications, Department of Psychology

Psychology, Department of

2005

\title{
Mixed Methods Research Designs in Counseling Psychology
}

William E. Hanson

University of Nebraska-Lincoln, whanson@purdue.edu

John W. Creswell

University of Nebraska-Lincoln, jcreswell1@unl.edu

Vicki L. Plano Clark

University of Nebraska-Lincoln, vicki.planoclark@uc.edu

Kelly S. Petska

University of Nebraska-Lincoln

J. David Creswell

University of California, Los Angeles

Follow this and additional works at: https://digitalcommons.unl.edu/psychfacpub

Part of the Psychiatry and Psychology Commons

Hanson, William E.; Creswell, John W.; Plano Clark, Vicki L.; Petska, Kelly S.; and Creswell, J. David, "Mixed Methods Research Designs in Counseling Psychology" (2005). Faculty Publications, Department of Psychology. 373.

https://digitalcommons.unl.edu/psychfacpub/373

This Article is brought to you for free and open access by the Psychology, Department of at DigitalCommons@University of Nebraska - Lincoln. It has been accepted for inclusion in Faculty Publications, Department of Psychology by an authorized administrator of DigitalCommons@University of Nebraska - Lincoln. 
Published in Journal of Counseling Psychology 52:2 (2005), pp. 224-235; doi 10.1037/0022-0167.52.2.224

Copyright (c) 2005 American Psychological Association. Used by permission.

"This article may not exactly replicate the final version published in the APA journal. It is not the copy of record."

An earlier version of this article was presented at the 111th Annual Convention of the American Psychological Association, Toronto, Ontario, Canada, August 2003. The authors thank Patricia Cerda and Carey Pawlowski, who assisted in identifying and locating published mixed methods studies.

\title{
Mixed Methods Research Designs in Counseling Psychology
}

\author{
William E. Hanson, Department of Educational Psychology, University of Nebraska-Lincoln \\ John W. Creswell, Department of Educational Psychology and Office of Qualitative and Mixed Methods Research, \\ University of Nebraska-Lincoln, and Department of Family Medicine, University of Michigan \\ Vicki L. Plano Clark, Department of Educational Psychology, Office of Qualitative and Mixed Methods Research, \\ and Department of Physics and Astronomy, University of Nebraska-Lincoln \\ Kelly S. Petska, Department of Educational Psychology, University of Nebraska-Lincoln \\ J. David Creswell, Department of Psychology, University of California, Los Angeles \\ Corresponding authors - William E. Hanson, Counseling Psychology Program, 228 TEAC, University of Nebraska-Lincoln, \\ Lincoln, NE 68588-0345, email whanson1@unl.edu , and John W. Creswell, Department of Educational Psychology, \\ 241 TEAC, University of Nebraska-Lincoln, Lincoln, NE 68588-0345, email jcreswell1@unl.edu
}

\begin{abstract}
With the increased popularity of qualitative research, researchers in counseling psychology are expanding their methodologies to include mixed methods designs. These designs involve the collection, analysis, and integration of quantitative and qualitative data in a single or multiphase study. This article presents an overview of mixed methods research designs. It defines mixed methods research, discusses its origins and philosophical basis, advances steps and procedures used in these designs, and identifies 6 different types of designs. Important design features are illustrated using studies published in the counseling literature. Finally, the article ends with recommendations for designing, implementing, and reporting mixed methods studies in the literature and for discussing their viability and continued usefulness in the field of counseling psychology.
\end{abstract}

Over the past 25 years, numerous calls for increased methodological diversity and alternative research methods have been made (Gelso, 1979; Goldman, 1976; Howard, 1983). These calls have led to important discussions about incorporating qualitative methods in counseling research and including qualitative studies in traditional publication outlets (Hoshmand, 1989; Maione \& Chenail, 1999; Morrow \& Smith, 2000). They have also led to discussions about integrating quantitative and qualitative methods, commonly referred to as mixed methods research.

In the social sciences at large, mixed methods research has become increasingly popular and may be considered a legitimate, stand-alone research design (Creswell, 2002, 2003; Greene, Caracelli, \& Graham, 1989; Tashakkori \& Teddlie, 1998, 2003). It may be defined as "the collection or analysis of both quantitative and qualitative data in a single study in which the data are collected concurrently or sequentially, are given a priority, and involve the integration of the data at one or more stages in the process of research" (Creswell, Plano Clark, Gutmann, \& Hanson, 2003, p. 212). When both quantitative and qualitative data are included in a study, researchers may enrich their results in ways that one form of data does not allow (Brewer \& Hunter, 1989; Tashakkori \& Teddlie, 1998).
Using both forms of data, for example, allows researchers to simultaneously generalize results from a sample to a population and to gain a deeper understanding of the phenomenon of interest. It also allows researchers to test theoretical models and to modify them based on participant feedback. Results of precise, instrument-based measurements may, likewise, be augmented by contextual, field-based information (Greene \& Caracelli, 1997).

Despite the availability of mixed-methods-related books, chapters, and journal articles, virtually nothing has been written about mixed methods research designs in applied psychology, generally, or in counseling psychology, specifically. Cursory examination of the three editions of the Handbook of Counseling Psychology (e.g., Brown \& Lent, 2000), of popular research design texts (e.g., Heppner, Kivlighan, \& Wampold, 1999), and of mainstream, peer-reviewed journals (e.g., Journal of Counseling $\mathcal{E}$ Development, The Counseling Psychologist) reinforces this assertion. The general absence of discussions on mixed methods research designs may be due to a number of factors, including the historical precedent of favoring quantitative and experimental methods in psychology (Gergen, 2001; Waszak \& Sines, 2003), the difficulty in learning and applying both types of methods (Behrens \& Smith, 1996; Ponterotto \& 
Grieger, 1999), and the general lack of attention given to diverse methodological approaches in graduate education and training (Aiken, West, Sechrest, \& Reno, 1990). However, with so few resources available, answers to the following types of questions remain elusive and somewhat difficult to find: What is mixed methods research? What types of mixed methods studies have been published in counseling? How should mixed methods studies be conducted and reported in the literature?

The purpose of this article is to help answer these questions by introducing mixed methods research designs to counseling psychologists. ${ }^{1}$ Our goal is to help counseling researchers and educators become more familiar with mixed methods terminology, procedures, designs, and key design features. Articles by Goodyear, Tracey, Claiborn, Lichtenberg, and Wampold (2005) and Beck (2005) introduce two specific methodological approaches-ideographic concept mapping and ethnographic decision tree modeling, respectively - and serve to further familiarize researchers and educators with mixed methods research designs.

The present article is divided into three sections. In the first section, we present an overview of mixed methods research, including its origins and philosophical basis, rationales, basic steps in designing a mixed methods study, and procedural notations. We also present a typology for classifying different types of mixed methods research designs. In the second section, we use mixed methods studies published in counseling to illustrate each of the designs and key design features discussed. In the third and final section, we offer recommendations for conducting and publishing mixed methods research.

\section{Overview of Mixed Methods Research}

The historical evolution of mixed methods research has not been traced completely by any one author or source, although Datta (1994) and Tashakkori and Teddlie (1998, 2003) have identified many of the major developmental milestones. The brief overview presented here attempts to incorporate and build on their analyses.

\section{Origins and Philosophical Basis}

The use of multiple data collection methods dates back to the earliest social science research. It was, however, Campbell and Fiske's (1959) study of the validation of psychological traits that brought multiple data collection methods into the spotlight. In their classic study, the multitrait-multimethod matrix was designed to rule out method effects; that is, to allow one to attribute individual variation in scale scores to the personality trait itself rather than to the method used to measure it. Although Campbell and Fiske focused on collecting multiple quantitative data, their work was instrumental in encouraging the use of multiple methods and the collection of multiple forms of data in a single study (Sieber, 1973). Taken one step further, the term triangulation, borrowed from military naval science to signify the use of multiple reference points to locate an object's exact position, was later used to suggest that quantitative and qualitative data could be complementary. Each could, for example, "uncover some unique variance which otherwise may have been neglected by a single method" (Jick, 1979, p. 603).
Over time, mixed methods research has gradually gained momentum as a viable alternative research method. Over the past 15 years, at least 10 mixed methods textbooks have been published (Bamberger, 2000; Brewer \& Hunter, 1989; Bryman, 1988; Cook \& Reichardt, 1979; Creswell, 2002, 2003; Greene \& Caracelli, 1997; Newman \& Benz, 1998; Reichardt \& Rallis, 1994; Tashakkori \& Teddlie, 1998). Recently, the Handbook of Mixed Methods in Social and Behavioral Research was published (Tashakkori \& Teddlie, 2003). In addition, journals such as Field Methods and Quantity and Quality are devoted to publishing mixed methods research. International online journals (see Forum: Qualitative Social Research at http:/ / qualitative-research.ne) and Web sites (e.g., http://www.fiu.edu/ bridges/ people.htm) provide easy access, resources, and hands-on experiences for interested researchers. Despite this growth and development, a number of controversial issues and debates have limited the widespread acceptance of mixed methods research.

Two important and persistent issues, the paradigm-method fit issue and the "best" paradigm issue, have inspired considerable debate regarding the philosophical basis of mixed methods research. The paradigm-method fit issue relates to the question "Do philosophical paradigms (e.g., postpositivism, constructivism) and research methods have to fit together?" This issue first surfaced in the 1960s and 70s, primarily as a result of the increasing popularity of qualitative research and the identification of philosophical distinctions between traditional postpositivist and naturalistic research. Guba and Lincoln (1988), for example, identified paradigm differences between postpositivist philosophical assumptions and naturalistic assumptions in terms of epistemology (how we know what we know), ontology (the nature of reality), axiology (the place of values in research), and methodology (the process of research). This led to a dichotomy between traditional inquiry paradigms and naturalistic paradigms.

Some researchers have argued, for example, that a postpositivist philosophical paradigm, or worldview, could be combined only with quantitative methods and that a naturalistic worldview could be combined only with qualitative methods. This issue has been referred to as the "paradigm debate" (Reichardt \& Rallis, 1994). From this perspective, mixed methods research was viewed as untenable (i.e., incommensurable or incompatible) because certain paradigms and methods could not "fit" together legitimately (Smith, 1983). Reichardt and Cook (1979) countered this viewpoint, however, by suggesting that different philosophical paradigms and methods were compatible. In their article, they argued that paradigms and methods are not inherently linked, citing a variety of examples to support their position (e.g., quantitative procedures are not always objective, and qualitative procedures are not always subjective). Indeed, the perspective exists today that multiple methods may be used in a single research study to, for example, take advantage of the representativeness and generalizability of quantitative findings and the indepth, contextual nature of qualitative findings (Greene \& Caracelli, 2003).

The best paradigm issue relates to the question "What philosophical paradigm is the best foundation for mixed methods research?" This issue, like the paradigm-method fit issue, has multiple perspectives (Tashakkori \& Teddlie, 2003). One per- 
spective is that mixed methods research uses competing paradigms intentionally, giving each one relatively equal footing and merit. This "dialectical" perspective recognizes that using competing paradigms gives rise to contradictory ideas and contested arguments, features of research that are to be honored and that may not be reconciled (Greene \& Caracelli, 1997, 2003). Such oppositions reflect different ways of making knowledge claims, and we advocate for honoring and respecting the different paradigmatic perspectives that researchers bring to bear on a study. In an earlier publication, we identified six different mixed methods research designs and discussed how the underlying theoretical lenses, or paradigms, may differ, depending on the type of design being used (Creswell et al., 2003). This perspective maintains that mixed methods research may be viewed strictly as a "method," thus allowing researchers to use any number of philosophical foundations for its justification and use. The best paradigm is determined by the researcher and the research problem - not by the method.

Another perspective is that pragmatism is the best paradigm for mixed methods research (Tashakkori \& Teddlie, 2003). Pragmatism is a set of ideas articulated by many people, from historical figures such as Dewey, James, and Pierce to contemporaries such as Murphy, Rorty, and West. It draws on many ideas including using "what works," using diverse approaches, and valuing both objective and subjective knowledge (Cherryholmes, 1992). Rossman and Wilson (1985) were among the first to associate pragmatism with mixed methods research. They differentiated between methodological purists, situationalists, and pragmatists. The purists believed that quantitative and qualitative methods derived from different, mutually exclusive, epistemological and ontological assumptions about research. The situationalists believed that both methods have value (similar to the dialectical perspective mentioned earlier) but that certain methods are more appropriate under certain circumstances. The pragmatists, in contrast, believed that, regardless of circumstances, both methods may be used in a single study. For many mixed methods researchers, then, pragmatism has become the answer to the question of what is the best paradigm for mixed methods research. Recently, Tashakkori and Teddlie (2003) have attempted to formally link pragmatism and mixed methods research, arguing that, among other things, the research question should be of primary importance-more important than either the method or the theoretical lens, or paradigm, that underlies the method. At least 13 other prominent mixed methods researchers and scholars also believe that pragmatism is the best philosophical basis of mixed methods research (Tashakkori \& Teddlie, 2003).

\section{Rationales, Basic Steps in Designing a Mixed Methods Study, and Procedural Notations}

Rationales. In the mid-1980s, scholars began expressing concern that researchers were indiscriminately mixing quantitative and qualitative methods and forms of data without acknowledging or articulating defensible reasons for doing so (Greene et al., 1989; Rossman \& Wilson, 1985). As a result, different reasons, or rationales, for mixing both forms of data in a single study were identified. Greene et al. (1989), for example, identified a number of rationales for combining data collection methods. These rationales went above and beyond the traditional notion of triangulation. Specifically, quantitative and qualitative methods could be combined to use results from one method to elaborate on results from the other method (complementarity), use results from one method to help develop or inform the other method (development; see Goodyear et al., 2005, and Beck, 2005), recast results from one method to questions or results from the other method (initiation), and extend the breadth or range of inquiry by using different methods for different inquiry components (expansion). Thus, they provided not only rationales for mixing methods and forms of data but also names for them.

Recently, mixed methods researchers have expanded the reasons for conducting a mixed methods investigation (Mertens, 2003; Newman, Ridenour, Newman, \& DeMarco, 2003; Punch, 1998). We agree with Mertens (2003) and Punch (1998), who suggested that mixed methods investigations may be used to (a) better understand a research problem by converging numeric trends from quantitative data and specific details from qualitative data; (b) identify variables/constructs that may be measured subsequently through the use of existing instruments or the development of new ones; (c) obtain statistical, quantitative data and results from a sample of a population and use them to identify individuals who may expand on the results through qualitative data and results; and (d) convey the needs of individuals or groups of individuals who are marginalized or underrepresented.

For a comprehensive, in-depth discussion of rationale issues, the reader is referred to Newman et al. (2003).

Basic steps in designing a mixed methods study. Designing a mixed methods study involves a number of steps, many of which are similar to those taken in traditional research methods. These include deciding on the purpose of the study, the research questions, and the type of data to collect. Designing a mixed methods study, however, also involves at least three additional steps. These include deciding whether to use an explicit theoretical lens, identifying the data collection procedures, and identifying the data analysis and integration procedures (Creswell, 1999; Greene \& Caracelli, 1997; Morgan, 1998; Tashakkori \& Teddlie, 1998). These steps occur more or less sequentially, with one informing and influencing the others.

The first step involves deciding whether to use an explicit theoretical lens. As used here, the term theoretical lens refers to the philosophical basis, or paradigm, (e.g., postpositivism, constructivism, feminism) that underlies a researcher's study and subsequent methodological choices (Crotty, 1998). It is an umbrella term that may be distinguished from broader epistemologies (e.g., objectivism, subjectivism), from narrower methodologies (e.g., experimental research), and from, narrower still, methods (e.g., random sampling, interviews). Recognizing that all researchers bring implicit theories and assumptions to their investigations, researchers at this initial stage must decide whether they are going to view their study from a paradigmatic base (e.g., postpositivism, constructivism) that does not necessarily involve a goal of social change or from an advocacy-based lens such as feminism. Our use of the term advocacy is similar to what Ponterotto (2005) refers to as a "critical/emancipatory" paradigm. In any event, the outcome of this decision informs and influences the methodology and the methods used in the study, as well as the use of the study's findings. 


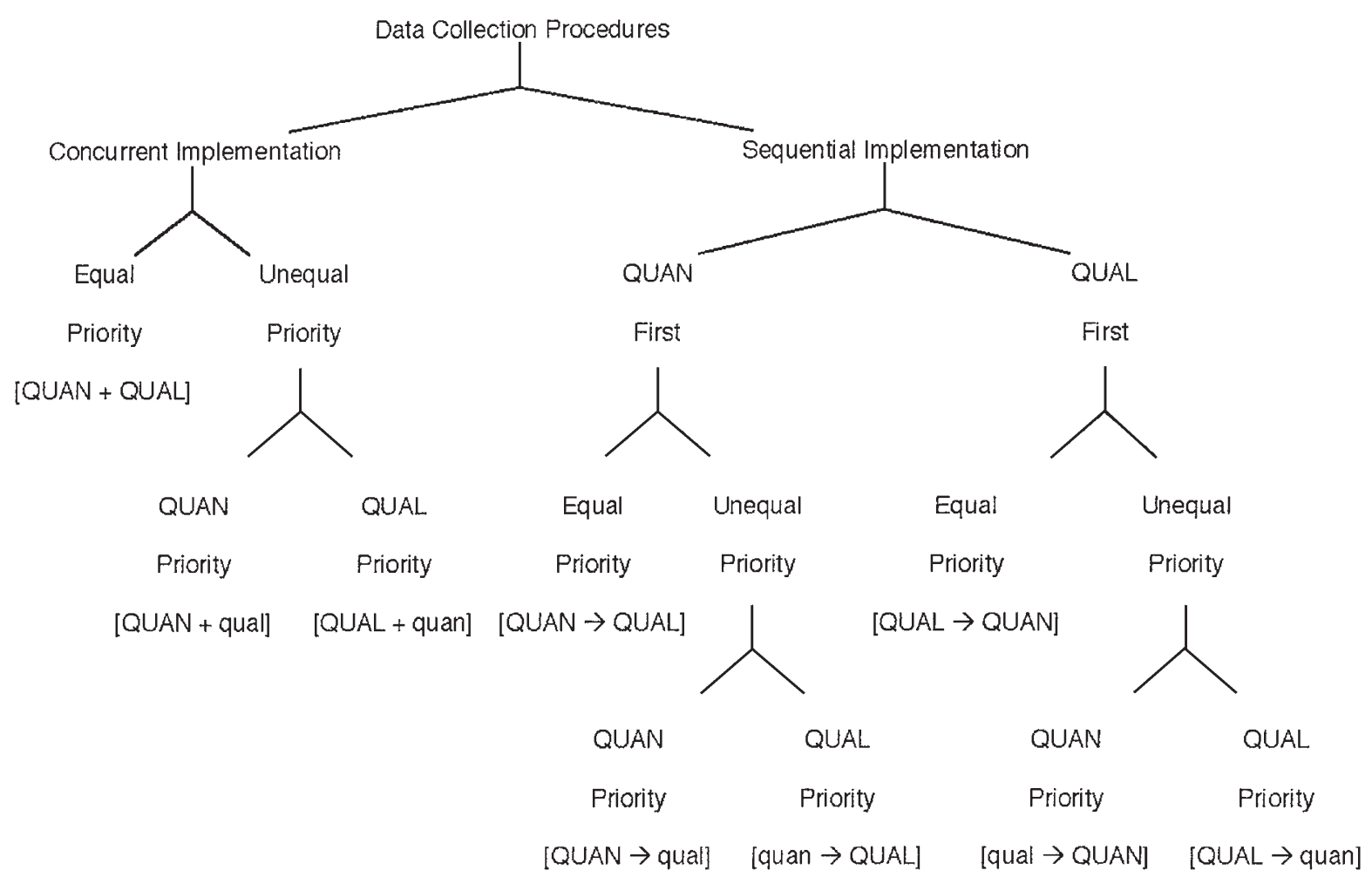

Figure 1. Options related to mixed methods data collection procedures. QUAN = quantitative data was prioritized; QUAL = qualitative data was prioritized; qual = lower priority given to the qualitative data; quan = lower priority given to the quantitative data.

If, for example, a feminist lens is used in a mixed methods study, then the gendered perspective provides a deductive lens that informs the research questions asked at the beginning of the study and the advocacy outcomes advanced at the end (cf. Mertens, 2003). Within the field of counseling psychology, the research question might be "How does a counselor's level of self-disclosure affect a client's perception of empowerment?" Answering this question may lead to more empowering, research-informed, counselor-client interactions and to overt attempts to change how counselors are trained and supervised.

The second step involves deciding how data collection will be implemented and prioritized. Implementation refers to the order in which the quantitative and qualitative data are collected, concurrently or sequentially, and priority refers to the weight, or relative emphasis, given to the two types of data, equal or unequal (Creswell et al., 2003; Morgan, 1998). A counseling researcher could, in the example above, collect data sequentially, first collecting quantitative survey data related to clients' postsession levels of perceived empowerment and then collecting qualitative interview data. The interview data could then be used to corroborate, refute, or augment findings from the survey data. As a result, priority in this hypothetical study would be unequal. Unequal priority occurs when a researcher emphasizes one form of data more than the other, starts with one form as the major component of a study, or collects one form in more detail than the other (Morgan, 1998). Figure 1 shows many of the options related to this step.
The third step involves deciding the point at which data analysis and integration will occur. In mixed methods studies, data analysis and integration may occur by analyzing the data separately, by transforming them, or by connecting the analyses in some way (Caracelli \& Green, 1993; Onwuegbuzie \& Teddlie, 2003; Tashakkori \& Teddlie, 1998). A counseling researcher could, for example, analyze the quantitative and qualitative data separately and then compare and contrast the two sets of results in the discussion. As an alternative strategy, themes that emerged from the qualitative interview data could be transformed into counts or ratings and subsequently compared to the quantitative survey data. Another option would be to connect the data analyses. To do this, the researcher could analyze the survey data, create a categorical variable that helps explain the outcome variance, and conduct follow-up interviews with individuals who were representative of each of the categories. For example, on the basis of results from the survey data, a typology of empowering and disempowering counselor self-disclosures, or levels of self-disclosure, could be developed. The researcher could then interview a subsample of clients (e.g., some who felt empowered and some who felt disempowered). In this way, results from the quantitative analysis would be connected to the qualitative data collection and analysis, primarily by aiding in the identification and selection of individuals to participate in the follow-up interviews.

Procedural notations. Reminiscent of the notation system developed by Campbell and Stanley (1966), which used Xs and 
Designs

Sequentia! Explanatory

Sequential Exploratory

Sequential Transformative

Concurrent Triangulation

Concurrent Nested
Procedural Notations

QUAN $\rightarrow$ qual

QUAL $\rightarrow$ quan
QUAN + QUAL

$\searrow K$

Results

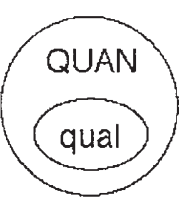

or
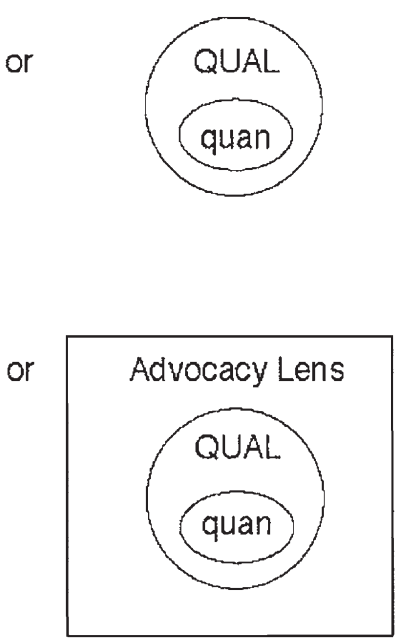

Figure 2. Typology for classifying mixed methods research designs. QUAN = quantitative data was prioritized; QUAL = qualitative data was prioritized; qual = lower priority given to the qualitative data; quan = lower priority given to the quantitative data.

Os to represent different experimental procedures, Morse (1991, 2003) developed a system for representing different mixed methods procedures. Instead of Xs and Os, however, her system uses plus $(+)$ symbols and arrows $(\rightarrow)$ as well as capital and lowercase letters. A plus sign indicates that quantitative and qualitative data are collected concurrently (at the same time), and an arrow indicates that they are collected sequentially (one followed by the other). The use of capital letters indicates higher priority for a particular method. Lowercase letters, in turn, indicate lower priority. By displaying mixed methods procedures graphically, readers may identify, at a glance, the implementation and the priority of the data collection procedures (see Figure 1). For example, QUAN $\rightarrow$ qual indicates a quantitatively driven sequential study, where quantitative data collection is followed by qualitative data collection with unequal priority, and QUAL + QUAN indicates a qualitatively and quantitatively driven concurrent study, where qualitative and quantitative data collection occur at the same time and are given equal priority.

\section{Types of Mixed Methods Research Designs}

Several authors have developed typologies of mixed methods research designs, drawing mostly from approaches used in evaluation (Greene et al., 1989), nursing (Morse, 1991), public health (Steckler, McLeroy, Goodman, Bird, \& McCormick, 1992), and education research (Creswell, 2002). Classification systems that use acceptable, standardized names and descriptive categories are still being developed. As one example, Creswell et al. (2003) developed a parsimonious system for classifying mixed methods research designs. As shown in Figure 2 , there are six primary types of designs: three sequential (explanatory, exploratory, and transformative) and three concurrent (triangulation, nested, and transformative). Each varies with respect to its use of an explicit theoretical/advocacy lens, approach to implementation (sequential or concurrent data collection procedures), priority given to the quantitative and qualitative data (equal or unequal), stage at which the data are analyzed and integrated (separated, transformed, or 
connected), and procedural notations. Because mixed methods designs are, generally speaking, complex, it is important to understand subtle differences and nuances between and among them. To facilitate this understanding, we next describe each of the six designs, beginning with sequential designs.

Sequential designs. There are three types of sequential designs: sequential explanatory, sequential exploratory, and sequential transformative. Sequential explanatory designs do not use an explicit advocacy lens. In these designs, quantitative data are collected and analyzed, followed by qualitative data. Priority is usually unequal and given to the quantitative data. Qualitative data are used primarily to augment quantitative data. Data analysis is usually connected, and integration usually occurs at the data interpretation stage and in the discussion. These designs are particularly useful for, as its name suggests, explaining relationships and/or study findings, especially when they are unexpected.

Sequential exploratory designs also do not use an explicit advocacy lens. In these designs, qualitative data are collected and analyzed first, followed by quantitative data. Priority is usually unequal and given to the qualitative data. Quantitative data are used primarily to augment qualitative data. Data analysis is usually connected, and integration usually occurs at the data interpretation stage and in the discussion. These designs are useful for exploring relationships when study variables are not known, refining and testing an emerging theory, developing new psychological test/assessment instruments based on an initial qualitative analysis, and generalizing qualitative findings to a specific population.

In contrast to the other two sequential designs, sequential transformative designs use an explicit advocacy lens (e.g., feminist perspectives, critical theory), which is usually reflected in the purpose statement, research questions, and implications for action and change. In these designs, quantitative data may be collected and analyzed, followed by qualitative data, or conversely, qualitative data may be collected and analyzed, followed by quantitative data. Thus, either form of data may be collected first, depending on the needs and preferences of the researchers. Priority may be unequal and given to one form of data or the other or, in some cases, equal and given to both forms of data. Data analysis is usually connected, and integration usually occurs at the data interpretation stage and in the discussion. These designs are useful for giving voice to diverse or alternative perspectives, advocating for research participants, and better understanding a phenomenon that may be changing as a result of being studied.

Concurrent designs. Similar to sequential mixed methods research designs, there are three types of concurrent designs: concurrent triangulation, concurrent nested, and concurrent transformative. In concurrent triangulation designs, quantitative and qualitative data are collected and analyzed at the same time. Priority is usually equal and given to both forms of data. Data analysis is usually separate, and integration usually occurs at the data interpretation stage. Interpretation typically involves discussing the extent to which the data triangulate or converge. These designs are useful for attempting to confirm, cross-validate, and corroborate study findings.

In concurrent nested designs, like concurrent triangulation designs, quantitative and qualitative data are collected and analyzed at the same time. However, priority is usually unequal and given to one of the two forms of data - either to the quan- titative or qualitative data. The nested, or embedded, forms of data are, in these designs, usually given less priority. One reason for this is that the less prioritized form of data may be included to help answer an altogether different question or set of questions. Data analysis usually involves transforming the data, and integration usually occurs during the data analysis stage. These designs are useful for gaining a broader perspective on the topic at hand and for studying different groups, or levels, within a single study.

In contrast to the other two concurrent designs, concurrent transformative designs use an explicit advocacy lens (e.g., feminist perspectives, critical theory), which is usually reflected in the purpose statement, research questions, and implications for action and change. Quantitative and qualitative data are collected and analyzed at the same time. Priority may be unequal and given to one form of data or the other or, in some cases, equal and given to both forms of data. Data analysis is usually separate, and integration usually occurs at the data interpretation stage or, if transformed, during data analysis. Similar to sequential transformative designs, these designs are useful for giving voice to diverse or alternative perspectives, advocating for research participants, and better understanding a phenomenon that may be changing as a result of being studied.

\section{Illustration of Mixed Methods Research Designs and Key Design Features}

In this section, we use studies published in the counseling literature to illustrate each of the six types of mixed methods research designs. In so doing, conceptual issues, such as implementation, priority, and data analysis and integration, may become more concrete and easier to understand. We also use these studies to highlight potential publication outlets and topics; the extent to which they include an explicit purpose statement, research questions, and rationale for using a mixed methods design; the data collection procedures; and the data analysis procedures. These design features are important ways of characterizing mixed methods studies. They offer insights into the complexities of this type of research and serve as signposts and markers for identifying, understanding, and evaluating the different types of designs.

To identify published mixed methods studies, we searched the PsycINFO computer database three times between August 2001 and May 2002, locating all counseling-related journal articles written in English. We then back-checked reference lists of the articles to identify other studies that may have been missed initially. This search procedure resulted in the identification of 22 studies. These studies were published between 1986 and 2000. Table 1 lists the design features of each.

Five of the six types of mixed methods research designs appeared in the counseling literature during the designated time period. Concurrent triangulation was the most common type of design used $(32 \%, n=7)$, followed by concurrent nested designs $(27 \%, n=6)$, sequential explanatory designs $(23 \%, n=$ $5)$, sequential exploratory designs $(14 \%, n=3)$, and concurrent transformative designs $(4 \%, n=1)$. No sequential transformative designs were used, and none of the studies used procedural notations to depict their design.

Luzzo (1995) used a concurrent triangulation design to study gender differences in career maturity and perceived barriers to career development. Four hundred one undergraduate students 
Table 1. Design Features of Mixed Methods Studies Published in Counseling

\begin{tabular}{|c|c|c|c|c|}
\hline Study & Design & Topic & $\begin{array}{l}\text { Purpose or } \\
\text { RQs/rationale }\end{array}$ & Priority/analysis \\
\hline Aspenson et al. (1993) & Concurrent nested & Training/supervision & Yes/yes & QUAL + quan/connected \\
\hline Baker \& Siryk (1986) & Concurrent nested & Assessment & Yes/no & QUAN + qual/connected \\
\hline Balmer et al. (1998) & Concurrent transformative & Group counseling & No/yes & QUAN + QUAL/separate \\
\hline Balmer et al. (1996) & Concurrent triangulation & Individual counseling & No/yes & QUAN + QUAL/separate \\
\hline Blustein et al. (1997) & Concurrent nested & Vocational/career & Yes/yes & QUAL + quan/CDT \\
\hline Daughtry \& Kunkel (1993) & Sequential exploratory & Individual counseling & Yes/yes & qual $\rightarrow$ QUAN/connected \\
\hline Gaston \& Marmar (1989) & Concurrent nested & Individual counseling & Yes/yes & QUAN + qual/connected \\
\hline Good \& Heppner (1995) & Concurrent triangulation & Training/diversity & Yes/yes & QUAL + quan/SDT \\
\hline Guernina (1998) & Concurrent nested & Individual counseling & Yes/yes & QUAN + qual/separate \\
\hline Hill et al. (2000) & Concurrent triangulation & Individual counseling & Yes/yes & QUAN + QUAL/separate \\
\hline Luzzo (1995) & Concurrent triangulation & Vocational/career & Yes/yes & QUAN + QUAL/separate \\
\hline Paulson et al. (1999) & Sequential exploratory & Counseling process & Yes/yes & qual $\rightarrow$ QUAN/connected \\
\hline Payne et al. (1991) & Sequential exploratory & Individual counseling & Yes/yes & $($ quan $\rightarrow$ )qual $\rightarrow$ QUAN/CDT \\
\hline Poasa et al. (2000) & Sequential explanatory & Diversity & Yes/yes & quan $\rightarrow$ QUAL/separate \\
\hline Wampold et al. (1995) & Sequential explanatory & Vocational/career & Yes/yes & $\mathrm{QUAN} \rightarrow($ quan + QUAL $) /$ separate \\
\hline Williams et al. (1997) & Concurrent nested & Training/supervision & Yes/yes & QUAL + quan/SDT \\
\hline
\end{tabular}

Purpose or RQs (research questions)/rationale = whether or not the study included an explicit purpose statement, RQ, and/or rationale for using a mixed methods design. Priority/analysis = the weight, or relative emphasis, given to the quantitative and qualitative data/the point at which the data were analyzed and integrated. QUAL = qualitative data was prioritized; QUAN = quantitative data was prioritized; quan = lower priority given to the quantitative data; qual = lower priority given to the qualitative data; $\mathrm{CDT}=$ connected analyses with data transformation; $\mathrm{SDT}=$ separate analyses with data transformation.

participated in the quantitative part of the study, and 128 participated in the qualitative part. In this study, the author did not use an advocacy lens, stated the study's purpose and rationale for using a mixed methods design, implemented data collection concurrently (QUAN and QUAL at the same time), prioritized the data equally, and integrated the data after analyzing them (during the interpretation phase). Specifically, quantitative data, in the form of scores on three different measures, and qualitative data, in the form of tape-recorded responses to openended questions, were collected to examine career-related gender differences. After analyzing the quantitative and qualitative data separately, the results were triangulated (i.e., integrated), and consistent/overlapping gender differences were identified. Balmer (1994), Balmer, Seeley, and Bachengana (1996), Good and Heppner (1995), Hill et al. (2000), Martin, Goodyear, and Newton (1987), and Meier (1999) are other examples of studies that used concurrent triangulation designs.

Williams, Judge, Hill, and Hoffman (1997) also used a concurrent mixed methods research design. However, they used a concurrent nested design to study 'trainees', clients', and supervisors' perceptions of the trainees' personal reactions and management strategies during counseling sessions" (p. 391). Seven doctoral trainees, 30 volunteer clients, and 7 supervisors participated in the study. In this study, the authors did not use an advocacy lens, stated the study's purpose and rationale for using a mixed methods design, reported three research questions (2 QUAL and 1 quan, which focused on different issues), implemented data collection concurrently (quan and QUAL at the same time), prioritized the qualitative data, and integrated the data after analyzing/transforming them (during the in- terpretation phase). Specifically, qualitative data, in the form of written responses to open-ended questions, were collected to examine two different issues: the kinds of personal reactions trainees have during counseling sessions and the strategies that they use to manage their reactions. Quantitative data, in the form of pre- and postchange scores, were nested and collected to examine changes in trainee anxiety, counseling self-efficacy, management of countertransference issues, and general counseling skills. After analyzing the qualitative and quantitative data separately, the results were used to help answer the three research questions. Aspenson et al. (1993), Baker and Siryk (1986), Blustein, Phillips, Jobin-Davis, Finkelberg, and Rourke (1997), Gaston and Marmar (1989), and Guernina (1998) are other examples of studies that used concurrent nested designs.

In contrast to Luzzo (1995) and Williams et al. (1997), Palmer and Cochran (1988) used a sequential mixed methods research design. They used a sequential explanatory design to provide "an empirical test of parent effectiveness in a structured career development program for their children" (p. 71). Forty volunteer families participated in their study. The experimental group completed a self-guided intervention program, which was compared to a control group on parent-child relationship measures and career development outcomes. In this study, the authors used Bronfenbrunner's theory of human development and Super's theory of career development as explicit theoretical lenses, stated the study's purpose, implemented data collection sequentially (QUAN followed by QUAL), prioritized the data equally, and integrated the data after analyzing them (during the interpre- 
tation phase and in the discussion). Specifically, quantitative data, in the form of scores on three different measures, were collected and analyzed, followed by qualitative data, in the form of verbal responses to open-ended interviews. After the quantitative data were analyzed, parents were interviewed, either in person or by telephone, to "gain a narrative description of how the program went, with attention to problems and benefits. The questions were open-ended, intended to invite general comments rather than definitive answers" (Palmer \& Cochran, 1988, p. 73). The qualitative data were used to augment the quantitative data. The authors noted that the "qualitative data from the interviews tended to support quantitative results" (p. 74). The authors did not report any research questions or specify a rationale for using a mixed methods design. Chusid and Cochran (1989), Orndoff and Herr (1996), Poasa, Mallinckrodt, and Suzuki (2000), and Wampold et al. (1995) are other examples of studies that used sequential explanatory designs.

Paulson, Truscott, and Stuart (1999) also used a sequential mixed methods research design. However, they used a sequential exploratory design to study clients' perceptions of helpful experiences in counseling. Thirty-six clients and 12 counselors participated in the study. In this study, the authors did not use an advocacy lens, stated the study's purpose and rationale for using a mixed methods design, reported one research question (combined qual and QUAN), implemented data collection sequentially (qual followed by QUAN), prioritized the quantitative data, and connected the data analysis. Specifically, qualitative data, in the form of transcribed responses to a single, open-ended question (i.e., "What was helpful about counseling?"), were collected and analyzed, followed by quantitative data, in the form of a sorting and rating task. Quantitative data were included to augment the qualitative data and to develop a concept map of clients' responses to the open-ended question. Daughtry and Kunkel (1993) and Payne, Robbins, and Dougherty (1991) are other examples of studies that used sequential exploratory designs. The methodological approaches described by Goodyear et al. (2005) and Beck (2005) may also be considered examples of sequential exploratory designs.

In the only identified transformative mixed methods research design, Balmer, Gikundi, Nasio, Kihuho, and Plummer (1998) used a concurrent transformative design to "evaluate group counseling, based upon a unified theory, as an intervention strategy for men with an STD infection and to develop a more detailed understanding of sexual behavior that results in STD/HIV acquisition and transmission" (p. 34). Two hundred forty-two men who were Kenyan and infected with an STD and 6 counselors participated in this randomized clinical trial study. In this study, the authors used an explicit advocacy lens, stated the rationale for using a mixed methods design, implemented data collection concurrently (QUAN and QUAL at the same time), prioritized the data equally, and integrated the data after analyzing them (during the interpretation phase). Specifically, in terms of an advocacy ("participatory action research") lens, "the qualitative assessment process allowed the counseled groups to become collaborators in a joint project and perhaps it increased their commitment" (Balmer et al., 1998, p. 42). Thus, the research participants' perspectives were elicited and used to help validate the findings. Moreover, the authors reported that the participants changed as a result of their participation. In terms of implementation (data collection), quantitative data, in the form of pre- and postchange scores on five different measures and medical statistics, and qualitative data, in the form of observations, interviews, field notes, and documents, were collected simultaneously. After analyzing the quantitative and qualitative data separately, the results were triangulated (i.e., integrated) and compared to the existing literature in this area. The authors did not state the purpose explicitly or report any research questions. No other examples of concurrent transformative designs were identified in our search of the counseling literature.

No sequential transformative designs were identified either. Consequently, to illustrate this design, a counseling-related study from the human development literature is described here. In this study, Tolman and Szalacha (1999) used a sequential transformative design to "understand the dimensions of the experience of sexual desire for adolescent girls" (p. 8). Thirty females who were in 11th grade and who attended an urban high school $(n=15)$ and a suburban high school $(n=15)$ participated in the study. In this study, the authors used an explicit advocacy lens, stated the rationale for using a mixed methods design, reported three research questions (2 QUAL and 1 quan), implemented data collection sequentially (QUAL followed by quan followed by QUAL), prioritized the qualitative data, and connected the data analysis. Specifically, in terms of the advocacy lens, it was "explicitly feminist in nature," using "a feminist organizing principle of listening to and taking women's voices seriously...particularly in data collection and data reduction, as well as in data analysis and interpretation" (p. 11). Thus, a mixed methods design was used to create "an opportunity for girls to put into words and to name their experience in and questions about a realm of their lives that remains unspoken in the larger culture" (p. 13). Data were collected and analyzed in three sequential phases. In the first and third phases, qualitative data, in the form of transcribed narratives of private, one-on-one, semistructured interviews, were collected and analyzed. In the second phase, quantitative data, in the form of coded frequency data, were collected and analyzed. Results from the first analysis were used to inform the second phase of data collection, and similarly, results from the second analysis were used to inform the third phase of data collection. In the end, the results from the three analyses were triangulated and used to help answer the three research questions.

\section{Journals, Purpose Statements, Research Questions, and Rationales}

Mixed methods studies have been published in at least seven counseling-related journals: Counselling Psychology Quarterly (CPQ); Counselor Education and Supervision (CES); Journal of Counseling \& Development (JCD); Journal of Counseling Psychology (JCP), Professional Psychology: Research and Practice (PPRP), Psychotherapy: Theory, Research, Training, Practice; and The Counseling Psychologist (TCP). The investigations have targeted a range of topics of interest to the field (e.g., individual counseling, vocational/career, training/supervision; see Table 1).

A particularly important design feature of mixed methods studies is the extent to which they include an explicit purpose statement, research questions (RQs), and rationale for using both quantitative and qualitative methods and data in a study (Creswell et al., 2003). As alluded to previously, pur- 
pose statements and research questions serve as signposts and markers for identifying, understanding, and evaluating the different types of mixed methods research designs. They also shape the analyses and integration of the results. Having a well conceived rationale is also important because it indicates to the reader that the quantitative and qualitative methods and data were mixed intentionally and for defensible reasons.

In our sample, purpose statements, RQs, and rationales were included in 19 (86\%), 11 (50\%), and 19 (86\%) studies, respectively. All 19 studies that stated a purpose stated it explicitly. For example, Wampold et al. (1995), in a two-part study of differences in social skills across Holland types (Study 1) and of how people who are task-oriented (e.g., C, R, and I types) construct their social/work environments (Study 2), stated, "The purpose of Study 1 was to test the hypotheses about relative strengths and weaknesses in specified social skills for various types of people" (pp. 368) and "Study 2 was a qualitative study designed to examine the density and nature of social interactions produced by chemists in an academic setting" (pp. 371). Three studies (14\%) did not include purpose statements.

Across the 11 studies that included RQs, the number of RQs ranged from one to five, with a mean of 2.64 RQs $(S D=1.36)$. Five studies (45\%) included both quantitative and qualitative RQs. Three (27\%) included only quantitative RQs, one $(9 \%)$ included only qualitative, and two (18\%) included only combinations of quantitative and qualitative.

Across the 19 studies that stated a rationale for mixing methods and quantitative and qualitative data, 16 (84\%) stated it explicitly. For example, Gaston and Marmar (1989), in a time-series study of therapeutic change events, mentioned specifically the importance of including both forms of data:

The main thesis of this article is that quantitative and qualitative knowledge are both essential for the understanding of the change process in psychotherapy. Ideally, information from both paradigms should be acquired within single investigations. With the use of a study example, we attempt to illustrate the dual advantages of richer process-outcome findings provided by combining quantitative and qualitative approaches. (p. 169)

Three $(16 \%)$ of the 19 studies that reported a rationale did not state it explicitly. In these studies, it was implied and had to be inferred from the text. Three studies (14\%) did not indicate a rationale.

\section{Data Collection Procedures}

Fourteen mixed methods studies implemented data collection procedures concurrently (64\%), and 8 implemented them sequentially (36\%). Priority was distributed more or less evenly across studies, with 7 prioritizing quantitative data $(32 \%), 6$ prioritizing qualitative data $(27 \%)$, and 9 prioritizing both equally (41\%). Quantitative data consisted primarily of self-report, instrument-based data $(n=20 ; 91 \%)$, followed by rating tasks $(n=5 ; 23 \%)$ and by observation$(n=1 ; 4 \%)$ and physiology-based data $(n=1 ; 4 \%)$. Qualitative data consisted primarily of data based on individual or group interviews $(n=17 ; 77 \%)$, followed by observations/ field notes $(n=9 ; 41 \%)$ and by data based on existing materials $(n=4 ; 18 \%)$, including official records, personal documents, and archival data.

\section{Data Analysis Procedures}

Ten mixed methods studies (45\%) analyzed quantitative and qualitative data separately, before all of the data were collected or analyzed. Data analysis was connected in 7 studies $(32 \%)$, separated and transformed (e.g., qualitative data were transformed into quantitative scores) in 3 studies (14\%), and connected and transformed in 2 studies (9\%). Quantitative data analysis consisted primarily of descriptive, or exploratory, procedures $(n=20 ; 91 \%)$, followed by inferential, or confirmatory, procedures $(n=19 ; 86 \%)$. Qualitative data analysis consisted primarily of the identification of themes and relationships $(n=17 ; 77 \%)$, using, for example, grounded theory (Strauss \& Corbin, 1990) and consensual qualitative research (CQR; Hill, Thompson, \& Williams, 1997), followed by thick description ( $n=8 ; 36 \%$; Wolcott, 1994). Twenty (91\%) of the studies integrated the data at the interpretation stage, and 2 $(9 \%)$ integrated the data at the analysis stage.

In considering the 22 studies cited in this section, a number of general observations may be made. First, mixed methods studies have indeed been published in counseling journals, the majority of which were published in CPQ, JCP, JCD, or TCP during the 1990s. Second, concurrent designs, where quantitative and qualitative data are collected at the same time, were the most common type of design used. Third, researchers who published mixed methods studies tended to include purpose statements, research questions, and rationales for using these designs. None of the studies, however, used procedural notations to depict the design. Fourth, the priority for data collection was distributed equally between quantitative and qualitative data across the studies. Fifth, data analysis tended to occur separately, and integration of the results (i.e., triangulation) tended to occur at the interpretation stage and in the discussion-approaches to analysis and integration that are consistent with concurrent triangulation designs, the single most popular type of design that was used.

We are well aware that these observations are primarily descriptive in nature. In reviewing the studies, we did not attempt to critique or rate the quality of any of them. As descriptive categories and standardized evaluative criteria continue to evolve, it may become easier to offer more formal strengthsand weaknesses-based observations. We are also aware that, despite our systematic, 9-month-long literature search, it is quite likely that we missed a few studies, especially ones that have been published within the past few years. Despite these limitations, we hope that this section of the article is of heuristic value to readers.

\section{Recommendations}

The primary purpose of this article was to introduce mixed methods research to counseling researchers and educators. On the basis of our understanding of mixed methods procedures and designs, as well as the general observations noted above, we offer the following recommendations for designing, implementing, and reporting a mixed methods study.

1. We recommend that researchers attend closely to theoreti$\mathrm{cal} /$ paradigmatic issues. Attention should be paid to the theoretical lens that informs the investigation and to the priority that is assigned to the quantitative and qualitative data. Explicit statement of the researcher's lens is informa- 
tive. A postpositivist lens would, for example, be appropriate for a sequential explanatory design that prioritized the quantitative data, whereas a constructivist lens would be appropriate for a sequential exploratory design that prioritized the qualitative data. For transformative designs, an advocacy-based or transformative-emancipatory lens would be required, regardless of whether the quantitative or qualitative data were prioritized.

2. We recommend that researchers also attend closely to design and implementation issues, particularly to how and when data are collected (e.g., concurrently or sequentially). The study's purpose plays an important role here (Creswell, 1999). If, for example, the purpose is to triangulate or converge the results, then the data may be collected concurrently. However, elaboration of the results would require a sequential design.

3. In mixed methods studies, data analysis and integration may occur at almost any point in time (Creswell et al., 2003). As noted by Onwuegbuzie and Teddlie (2003), "The point at which the data analysis begins and ends depends on the type of data collected, which in turn depends on the sample size, which in turn depends on the research design, which in turn depends on the purpose" (p. 351). We recommend that researchers familiarize themselves with the analysis and integration strategies used in the mixed methods studies cited in this article as well as with those recommend by Caracelli and Green (1993) and Onwuegbuzie and Teddlie (2003).

4 . Because mixed methods studies require a working knowledge and understanding of both quantitative and qualitative methods, and because they involve multiple stages of data collection and analysis that frequently extend over long periods of time, we recommend that researchers work in teams. Working in teams allows researchers with expertise in quantitative methods and analyses, qualitative methods and analyses, and/or both to be involved directly in designing and implementing a mixed methods study.

5. In preparing a mixed methods manuscript, we recommend that researchers use the phrase mixed methods in the titles of their studies. We also recommend that, early on, researchers foreshadow the logic and progression of their studies by stating the study's purpose and research questions in the introduction. Clear, well written purpose statements and research questions that specify the quantitative and qualitative aspects of the study help focus the manuscript.

6. We recommend that, in the introduction, researchers explicitly state a rationale for mixing quantitative and qualitative methods and data (e.g., to triangulate the results, to extend the study's results). It is best to specify the advantages, for the specified research questions, that accrue from using both methods and data. Examples of good rationales may be found in Gaston and Marmar (1989) and Hill et al. (2000).

7. We recommend that, in the methods, researchers specify the type of mixed methods research design used (e.g., sequential explanatory mixed methods design) and include procedural notations such as those shown in Figures 1 and 2. By doing this, the field will be able to build a common vocabulary and shared understanding of the different types of designs available.

8. Finally, we recommend that counseling researchers and educators continue having candid discussions about the le- gitimacy and viability of mixed methods research. As one anonymous reviewer noted,

researchers [should] openly discuss their views on the integration of potentially distinct epistemological issues in using mixed designs. This may not always be necessary when the methods are relatively close with respect to assumptions about the nature of knowledge. However, when the methods are quite far apart...some exploration of the complexities of merging methodological perspectives would be quite helpful.

We strongly agree. Discussions of this nature may stimulate additional interest and future advancements in this emerging form of inquiry.

Many scholars have begun to describe mixed methods research as a legitimate, stand-alone research design ready to stand beside time-honored designs such as experiments, surveys, grounded theory studies, and ethnographies (Datta, 1994; Tashakkori \& Teddlie, 1998, 2003). Despite numerous challenges and obstacles, it has emerged as a viable alternative to purely quantitative or qualitative methods and designs. With studies available in the literature, and in this issue, to serve as models, and with the recommendations included here, counseling researchers and educators may be on the verge of a new generation of thinking about method and methodology.

\section{References}

Aiken, L. S., West, S. G., Sechrest, L., \& Reno, R. R. (1990). Graduate training in statistics, methodology, and measurement in psychology: A survey of $\mathrm{PhD}$ programs in North America. American Psychologist, 45, 721-734.

Aspenson, D. O., Gersh, T. L., Perot, A. R., Galassi, J. P., Schroeder, R., Kerick, S., Bulger, J., \& Brooks, L. (1993). Graduate psychology students' perceptions of the scientist-practitioner model of training. Counselling Psychology Quarterly, 6, 201-215.

Baker, R. W., \& Siryk, B. (1986). Exploratory intervention with a scale measuring adjustment to college. Journal of Counseling Psychology, 33, 31-38.

Balmer, D. H. (1994). The efficacy of a scientific and ethnographic research design for evaluating AIDS group counselling. Counselling Psychology Quarterly, 7, 429-440.

Balmer, D. H., Gikundi, E., Nasio, J., Kihuho, F., \& Plummer, F. A. (1998). A clinical trial of group counselling for changing highrisk sexual behaviour in men. Counselling Psychology Quarterly, $11,33-43$.

Balmer, D. H., Seeley, J., \& Bachengana, C. (1996). The role of counselling in community support for HIV/AIDS in Uganda. Counselling Psychology Quarterly, 9, 177-190.

Bamberger, M. (Ed.). (2000). Integrating quantitative and qualitative research in development projects. Washington, DC: World Bank.

Beck, K. A. (2005). Ethnographic decision tree modeling: A research method for counseling psychologists. Journal of Counseling Psychology, 52, 243-249.

Behrens, J. T., \& Smith, M. L. (1996). Data and data analysis. In D.Berliner \& B.Calfee (Eds.), The handbook of educational psychology (pp. 945-989). New York: Macmillan.

Blustein, D. L., Phillips, S. D., Jobin-Davis, K., Finkelberg, S. L., \& Rourke, A. E. (1997). A theory-building investigation of the school-to-work transition. The Counseling Psychologist, 25, 364-402.

Brewer, J., \& Hunter, A. (1989). Multimethod research: A synthesis of styles. Newbury Park, NJ: Sage. 
Brown, S. D., \& Lent, R. W. (2000). Handbook of counseling psychology (3rd ed.). New York: Wiley.

Bryman, A. (1988). Quantity and quality in social research. London: Routledge.

Campbell, D. T., \& Fiske, D. (1959). Convergent and discriminant validation by the multitrait-multimethod matrix. Psychological Bulletin, 56, 81-105.

Campbell, D. T., \& Stanley, J. C. (1966). Experimental and quasiexperimental designs for research. In N. L.Gage (Ed.), Handbook of research on teaching (pp. 1-76). Chicago: Rand McNally.

Caracelli, V. J., \& Greene, J. C. (1993). Data analysis strategies for mixed-method evaluation designs. Educational Evaluation and Policy Analysis, 15, 195-207.

Cherryholmes, C. C. (1992). Notes on pragmatism and scientific realism. Educational Researcher, 21, 13-17.

Chusid, H., \& Cochran, L. (1989). Meaning of career changes from the perspective of family roles and dramas. Journal of Counseling Psychology, 36, 34-41.

Cook, T. D., \& Reichardt, C. S. (Eds.). (1979). Qualitative and quantitative methods in evaluation research. Beverly Hills, CA: Sage.

Creswell, J. W. (1999). Mixed method research: Introduction and application. In T.Cijek (Ed.), Handbook of educational policy (pp. 455-472). San Deigo, CA: Academic Press.

Creswell, J. W. (2002). Educational research: Planning, conducting, and evaluating quantitative and qualitative approaches to research. Upper Saddle River, NJ: Merrill/Pearson Education.

Creswell, J. W. (2003). Research design: Quantitative, qualitative, and mixed methods approaches (2nd ed.). Thousand Oaks, CA: Sage.

Creswell, J. W., Plano Clark, V. L., Gutmann, M. L., \& Hanson, W. E. (2003). Advanced mixed methods research designs. In A.Tashakkori \& C.Teddlie (Eds.), Handbook of mixed methods in social and behavioral research (pp. 209-240). Thousand Oaks, CA: Sage.

Crotty, M. (1998). The foundations of social research: Meaning and perspective in the research process. London: Sage.

Datta, L. (1994). Paradigm wars: A basis for peaceful coexistence and beyond. In C. S.Reichardt \& S. F.Rallis (Eds.), The qualitative-quantitative debate: New perspectives (pp. 53-70). San Francisco: Jossey-Bass.

Daughtry, D., \& Kunkel, M. A. (1993). Experience of depression in college students: A concept map. Journal of Counseling Psychology, 40, 316-323.

Gaston, L., \& Marmar, C. R. (1989). Quantitative and qualitative analyses for psychotherapy research: Integration through time-series design. Psychotherapy, 26, 169-176.

Gelso, C. J. (1979). Research in counseling: Methodological and professional issues. The Counseling Psychologist, 8, 7-36.

Gergen, K. J. (2001). Psychological science in a postmodern context. American Psychologist, 56, 803-813.

Goldman, L. (1976). A revolution in counseling psychology. Journal of Counseling Psychology, 23, 543-552.

Good, G. E., \& Heppner, M. J. (1995). Students' perceptions of a gender issues course: A qualitative and quantitative examination. Counselor Education and Supervision, 34, 308-320.

Goodyear, R. K., Tracey, T. J. G., Claiborn, C. D., Lichtenberg, J. W., \& Wampold, B. E. (2005). Ideographic concept mapping in counseling psychology research: Conceptual overview, methodology, and an illustration. Journal of Counseling Psychology, 52, 236-242.

Greene, J. C., \& Caracelli, V. J. (Eds.). (1997). Advances in mixedmethod evaluation: The challenges and benefits of integrating diverse paradigms. (New Directions for Evaluation, No. 74). San Francisco: Jossey-Bass.
Greene, J. C., \& Caracelli, V. J. (2003). Making paradigmatic sense of mixed methods practice. In A.Tashakkori \& C.Teddlie (Eds.), Handbook of mixed methods in social and behavioral research (pp. 91-110). Thousand Oaks, CA: Sage.

Greene, J. C., Caracelli, V. J., \& Graham, W. F. (1989). Toward a conceptual framework for mixed-method evaluation designs. Educational Evaluation and Policy Analysis, 11, 255-274.

Guba, E. G., \& Lincoln, Y. S. (1988). Do inquiry paradigms imply inquiry methodologies?. In D. M.Fetterman (Ed.), Qualitative approaches to evaluation in education (pp. 89-115). New York: Praeger Publishers.

Guernina, Z. (1998). Adolescents with eating disorders: A pilot study. Counselling Psychology Quarterly, 11, 117-124.

Heppner, P. P., Kivlighan, D. M., Jr., \& Wampold, B. E. (1999). Research design in counseling (2nd ed.). Belmont, CA: Wadsworth.

Hill, C. E., Thompson, B. J., \& Williams, E. N. (1997). A guide to conducting consensual qualitative research. The Counseling Psychologist, 25, 517-572.

Hill, C. E., Zack, J. S., Wonnell, T. L., Hoffman, M. A., Rochlen, A. B., Goldberg, J. L., et al. (2000). Structured brief therapy with a focus on dreams or loss for clients with troubling dreams and recent loss. Journal of Counseling Psychology, 47, 90-101.

Hoshmand, L. L. S. T. (1989). Alternate research paradigms: A review and teaching proposal. The Counseling Psychologist, 17, 3-79.

Howard, G. S. (1983). Toward methodological pluralism. Journal of Counseling Psychology, 30, 19-21.

Jick, T. D. (1979). Mixing qualitative and quantitative methods: Triangulation in action. Administrative Science Quarterly, 24, 602-611.

Luzzo, D. A. (1995). Gender differences in college students' career maturity and perceived barriers in career development. Journal of Counseling \& Development, 73, 319-322.

Maione, P. V., \& Chenail, R. J. (1999). Qualitative inquiry in psychotherapy: Research on the common factors. In M. A.Hubble, B. L.Duncan, \& S. D.Miller (Eds.), The heart and soul of change: What works in therapy (pp. 57-88). Washington, DC: American Psychological Association.

Martin, J. S., Goodyear, R. K., \& Newton, F. B. (1987). Clinical supervision: An intensive case study. Professional Psychology: Research and Practice, 18, 225-235.

Meier, S. T. (1999). Training the practitioner-scientist: Bridging case conceptualization, assessment, and intervention. The Counseling Psychologist, 27, 846-869.

Mertens, D. M. (2003). Mixed methods and the politics of human research: The transformative-emancipatory perspective. In A.Tashakkori \& C.Teddlie (Eds.), Handbook of mixed methods in social and behavioral research (pp. 135-164). Thousand Oaks, CA: Sage.

Morgan, D. L. (1998). Practical strategies for combining qualitative and quantitative methods: Applications to health research. Qualitative Health Research, 8, 362-376.

Morrow, S. L., \& Smith, M. L. (2000). Qualitative research for counseling psychology. In S. D.Brown \& R. W.Lent (Eds.), Handbook of counseling psychology (3rd ed., (pp. 199-230). New York: Wiley.

Morse, J. M. (1991). Approaches to qualitative-quantitative methodological triangulation. Nursing Research, 40, 120-123.

Morse, J. M. (2003). Principles of mixed methods and multimethod research design. In A.Tashakkori \& C.Teddlie (Eds.), Handbook of mixed methods in social and behavioral research (pp. 189-208). Thousand Oaks, CA: Sage.

Newman, I., \& Benz, C. R. (1998). Qualitative-quantitative research methodology: Exploring the interactive continuum. Carbondale: University of Illinois Press. 
Newman, I., Ridenour, C. S., Newman, C., \& DeMarco, G. M. P., Jr. (2003). A typology of research purposes and its relationship to mixed methods. In A.Tashakkori \& C.Teddlie (Eds.), Handbook of mixed methods in social and behavioral research (pp. 167188). Thousand Oaks, CA: Sage.

Onwuegbuzie, A. J., \& Teddlie, C. (2003). A framework for analyzing data in mixed methods research. In A.Tashakkori \& C.Teddlie (Eds.), Handbook of mixed methods in social and behavioral research (pp. 351-383). Thousand Oaks, CA: Sage.

Orndoff, R. M., \& Herr, E. L. (1996). A comparative study of declared and undeclared college students on career uncertainty and involvement in career development activities. Journal of Counseling \& Development, 74, 632-640.

Palmer, S., \& Cochran, L. (1988). Parents as agents of career development. Journal of Counseling Psychology, 35, 71-76.

Paulson, B. L., Truscott, D., \& Stuart, J. (1999). Clients' perceptions of helpful experiences in counseling. Journal of Counseling Psychology, 46, 317-324.

Payne, E. C., Robbins, S. B., \& Dougherty, L. (1991). Goal directedness and older-adult adjustment. Journal of Counseling Psychology, 38, 302-308.

Poasa, K. H., Mallinckrodt, B., \& Suzuki, L. A. (2000). Causal attributions for problematic family interactions: A qualitative, cultural comparison of Western Samoa, American Samoa and the United States. The Counseling Psychologist, 28, 32-60.

Ponterotto, J. G. (2005). Qualitative research in counseling psychology: A primer on research paradigms and philosophy of science. Journal of Counseling Psychology, 52, 126-136.

Ponterotto, J. G., \& Grieger, I. (1999). Merging qualitative and quantitative perspectives in a research identity. In M.Kopala \& L.Suzuki (Eds.), Using qualitative methods in psychology (pp. 4962). Thousand Oaks, CA: Sage.

Punch, K. F. (1998). Introduction to social research: Quantitative and qualitative approaches. Thousand Oaks, CA: Sage.

Reichardt, C. S., \& Cook, T. D. (1979). Beyond qualitative versus quantitative methods. In T. D.Cook \& C. S.Reichardt (Eds.), Qualitative and quantitative methods in evaluation research (pp. 732). Beverly Hills, CA: Sage.

Reichardt, C. S., \& Rallis, S. F. (Eds.). (1994). The qualitative-quantitative debate: New perspectives. San Francisco: Jossey-Bass.
Rossman, G. B., \& Wilson, B. L. (1985). Numbers and words: Combing quantitative and qualitative methods in a single large-scale evaluation study. Evaluation Review, 9, 627-643.

Sieber, S. D. (1973). The integration of field work and survey methods. American Journal of Sociology, 78, 1335-1359.

Smith, J. K. (1983). Quantitative versus qualitative research: An attempt to clarify the issue. Educational Researcher, 12, 6-13.

Steckler, A., McLeroy, K. R., Goodman, R. M., Bird, S. T., \& McCormick, L. (1992). Toward integrating qualitative and quantitative methods: An introduction. Health Education Quarterly, 19, 1-8.

Strauss, A., \& Corbin, J. (Eds.). (1990). Basics of qualitative research: Ground theory procedures and techniques. Newbury Park, CA: Sage.

Tashakkori, A., \& Teddlie, C. (1998). Mixed methodology: Combining qualitative and quantitative approaches. Thousand Oaks, CA: Sage.

Tashakkori, A., \& Teddlie, C. (Eds.). (2003). Handbook of mixed methods in social and behavioral research. Thousand Oaks, CA: Sage.

Tolman, D. L., \& Szalacha, L. A. (1999). Dimensions of desire: Bridging qualitative and quantitative methods in a study of female adolescent sexuality. Psychology of Women Quarterly, 23, 7-39.

Wampold, B. E., Ankarlo, G., Mondin, G., Trinidad-Carrillo, M., Baumler, B., \& Prater, K. (1995). Social skills of and social environments produced by different Holland types: A social perspective on person-environment fit model. Journal of Counseling Psychology, 42, 365-379.

Waszak, C., \& Sines, M. C. (2003). Mixed methods in psychological research. In A.Tashakkori \& C.Teddlie (Eds.), Handbook of mixed methods in social and behavioral research (pp. 557-576). Thousand Oaks, CA: Sage.

Williams, E. N., Judge, A. B., Hill, C. E., \& Hoffman, M. A. (1997). Experiences of novice therapists in prepracticum: Trainees', clients', and supervisors' perceptions of therapists' personal reactions and management strategies. Journal of Counseling Psychology, 44, 390-399.

Wolcott, H. F. (1994). Transforming qualitative data: Description, analysis, and interpretation. Thousand Oaks, CA: Sage. 